\title{
Ultrastructure and Development of Vitrified/Warmed Bovine Oocytes Matured with 9-cis Retinoic Acid
}

\author{
AIDA RODRÍGUEZ, ${ }^{1}$ ENRIQUE GÓMEZ, ${ }^{1}$ ISAAC ANTOLÍN, ${ }^{2}$ PALOMA DUQUE, ${ }^{1,}$ \\ CARLOS O. HIDALGO ${ }^{1}$ CRISTINA ALONSO,${ }^{1}$ CAROLINA TAMARGO ${ }^{1}$ \\ LINA FERNÁNDEZ, ${ }^{3}$ MAITE CARBAJO, ${ }^{3}$ NIEVES FACAL, ${ }^{1}$ JOSÉ NÉSTOR CAAMAÑO, ${ }^{1}$ \\ and CARMEN DÍEZ ${ }^{1}$
}

\begin{abstract}
In this work we analyze the effects of vitrification on the ultrastructure and developmental ability of bovine oocytes matured in the presence of 9-cis-retinoic acid (RA). Bovine cumulus oocyte complexes (COCs) were matured in a basic medium containing $\mathbf{1 0} \%$ fetal calf serum (FCS), 9-cis-RA or polyvinyl alcohol (PVA). Mature oocytes were vitrified using the Open Pulled Straw method with minor modifications. A group of fresh and vitrified/warmed COCs was fixed for ultrastructural analysis, while the remaining oocytes were fertilized in vitro and cultured. Vitrification of mature oocytes produced high rates of degeneration regardless of the in vitro maturation protocol and low number of cleaved embryos. Development rates up to day 8 were similar between groups undergoing vitrification, which were lower than fresh controls. Morphologic alterations were observed in all groups of vitrified oocytes, although in vitro maturation in the presence of 9-cis-RA combined with vitrification led to higher ultrastructural damage. More research is needed to explain the low survival rates of the bovine oocyte after vitrification and warming.
\end{abstract}

\section{INTRODUCTION}

A LTHOUGH GAMETES were among the very first cells to be successfully cryopreserved, mammalian oocytes remain one of the most difficult cell types to cryopreserve successfully. The ultrastructure of the cumulus oocyte complexes (COC) is significantly affected by cryopreservation procedures. Several studies focused on cytoplasmic and nuclear alterations after cryopreservation within cumulus cells (CC) and the oocyte, ${ }^{1-7}$ concluded that the reduced developmental competence of cryopreserved oocytes depends on cryodamage inflicted to the oocyte. 7,8

In the bovine oocyte, the maturation stage in- fluences developmental competence after cryopreservation $^{1,7-11}$ with the metaphase II (MII) oocyte being more resistant to cryopreservation than immature oocytes. ${ }^{1,7-10}$ Also, the maturation system is known to condition the oocyte's ability to survive cryopreservation. ${ }^{8}$ Vitamin A (all-trans-retinol; $\mathrm{ROH}$ ) and its metabolites are regulators of cell growth, embryonic morphogenesis, and differentiation in many cell types. In our laboratory, the $\mathrm{ROH}$ metabolite, the 9cis-RA stimulates developmental competence of the oocyte during in vitro maturation (IVM) ${ }^{12,13}$ and during a period of meiotic inhibition prior to IVM. ${ }^{14}$ However, it is unknown whether 9cis-RA during IVM can benefit the viability of the oocyte after cryopreservation. The purpose

\footnotetext{
${ }^{1}$ Servicio Regional de Investigación y Desarrollo Agroalimentario (SERIDA), Gijón, Spain.

${ }^{2}$ Facultad de Medicina. Julián Clavería s/n. Universidad de Oviedo, Oviedo, Spain.

${ }^{3}$ Facultad de Veterinaria, Campus de Vegazana, Leon, Spain.

*Present address: Centro de Fertilización in vitro de Asturias (CEFIVA), Gijón, Spain.
} 
of this work was to analyze the effect of 9-cisRA during IVM on ultrastructure and viability of vitrified/warmed COCs.

\section{MATERIALS AND METHODS}

All chemicals were purchased from Sigma (Madrid, Spain) unless otherwise indicated.

\section{Collection of COCs}

Ovaries recovered from slaughtered cows were placed in $\mathrm{NaCl}$ solution $(9 \mathrm{mg} / \mathrm{mL})$ containing antibiotics (penicillin, $100 \mathrm{UI} / \mathrm{mL}$ and streptomycin sulfate, $100 \mu \mathrm{g} / \mathrm{mL}$ ) and maintained at $25^{\circ}-30^{\circ} \mathrm{C}$ until COCs collection. Visible follicles, 2 to $7 \mathrm{~mm}$ in size, were aspirated and COCs were selected and washed as previously reported. ${ }^{1}$

The COCs were in vitro matured in an IVM medium containing TCM 199 (Invitrogen, Barcelona, Spain) $26 \mathrm{mM} \mathrm{HNaCO} 3$, porcine follicle stimulating hormone (pFSH) $(1 \mu \mathrm{g} / \mathrm{mL}), \mathrm{LH}$ (5 $\mu \mathrm{g} / \mathrm{mL})$, and $17 \beta$-estradiol $(1 \mu \mathrm{g} / \mathrm{mL})$. Experimental groups were defined adding to IVM medium: (1) 10\% fetal calf serum (FCS) (control); (2) $0.3 \mathrm{~g} / \mathrm{L}$ PVA plus 9-cis-RA $5 \mathrm{nM}$, and (3) 0.3 $\mathrm{g} / \mathrm{L}$ PVA. Incubations were performed during $22 \mathrm{~h}$ in 4-well dishes (Nunc, Biocen, Spain) at $39^{\circ} \mathrm{C}$ in $5 \% \mathrm{CO}_{2}$ under air and high humidity.

\section{Vitrification and warming}

Vitrification and warming of COCs followed the Open-Pulled Straw (OPS) method described by Vieira et al. ${ }^{15}$ with minor modifications as recently reported. ${ }^{1}$ Vitrification solutions consisted in TCM 199-Hepes plus 20\% FCS with $10 \%$ EG plus $10 \%$ dimethyl sulfoxide $\left(\mathrm{Me}_{2} \mathrm{SO}\right)$ (vitrification solution 1), and TCM 199-Hepes plus $20 \%$ FCS with $20 \%$ EG plus $20 \%\left(\mathrm{Me}_{2} \mathrm{SO}\right)$ plus $0.5 \mathrm{M}$ sucrose (vitrification solution 2).

After warming, COCs were cultured for $2 \mathrm{~h}$ to accomplish the maturation period before being submitted to in vitro fertilization (IVF) and culture.

\section{In vitro fertilization}

Sperm separation was carried out using a swim-up procedure similar to that reported by
Parrish et al. (16) and IVF was performed as is usually done in our laboratory. ${ }^{1}$

\section{Embryo culture}

Presumptive zygotes were gently passed through a small gauge pipette to eliminate CC and sperm, washed three times in HM, and twice in culture medium.

Before culture, morphologic appearance of the ova was evaluated under a stereomicroscope. Only presumptive zygotes with normal morphology were cultured. Embryo culture was performed in modified synthetic oviduct fluid (SOF) containing amino acids, citrate, and myoinositol. ${ }^{17}$ The FCS (5\%) was added at $42 \mathrm{~h}$ postfertilization (post-FIV). Incubations were carried out at $39^{\circ} \mathrm{C}, 5 \% \mathrm{CO}_{2}, 5 \% \mathrm{O}_{2}$, and $90 \% \mathrm{~N}_{2}$. Culture media were renewed at $66 \mathrm{~h}$ (day 3) and $138 \mathrm{~h}$ (day 6) post-FIV, and embryonic development was recorded on days $3,6,7$, and 8 .

\section{Experimental design}

The experiment analyzed the ability of the bovine oocytes to develop after vitrification/ warming and the oocyte ultrastructure after maturation in a defined medium containing 9-cisRA. We used as a control a maturation medium containing FCS, which was replaced by an experimental group with 9-cis-RA plus PVA. A group with PVA alone served to control the effect of merely replacing serum. Thus, the basic maturation medium consisted in TCM 19926 $\mathrm{mM} \mathrm{HNaCO}_{3}, \mathrm{pFSH}(1 \mu \mathrm{g} / \mathrm{mL})$, luteinizing hormone $(\mathrm{LH})(5 \mu \mathrm{g} / \mathrm{mL})$, and $17 \beta$-estradiol (1 $\mu \mathrm{g} / \mathrm{mL}$ ) to which we added: (1) $10 \%$ FCS (FCS group); (2) $0.3 \mathrm{~g} / \mathrm{L}$ PVA plus 9-cis-RA $5 \mathrm{nM}$ (RA group), and (3) $0.3 \mathrm{~g} / \mathrm{L}$ PVA (PVA group). Oocytes from each experimental group were processed fresh (i.e., unvitrified) as controls.

\section{Electron microscopy}

Vitrified/warmed oocytes and their corresponding fresh controls were fixed for ultrastructural analysis as previously described. ${ }^{1}$ We analyzed the degree of expansion in CC, ultrastructure of both CC and the oocyte focusing on organelle status, gap junctions (GJ) between CC and the oocyte, integrity of the plasmatic membrane and mitochondria, loca- 
Table 1. Cultured Embryos and Embryo Development Rates After Vitrification/Warming of Bovine Oocytes Submitted to Three Different In Vitro Maturation Protocols

\begin{tabular}{|c|c|c|c|c|c|c|c|}
\hline Group & $N$ & $R$ & $\begin{array}{l}\text { Day } 1 \\
\% \text { Cultured }\end{array}$ & $\begin{array}{c}\text { Day } 3 \\
\% \text { Cleaved }\end{array}$ & $\begin{array}{l}\text { Day } 3 \\
\% \text { 5-8 cells }\end{array}$ & $\begin{array}{l}\text { Day } 6 \\
\% \text { Mor + B1 }\end{array}$ & $\begin{array}{c}\text { Day } 7 \\
\% \text { Blastocysts }\end{array}$ \\
\hline FCS & 378 & 9 & $68.2 \pm 7.5$ & $39.4 \pm 6.1^{\mathrm{a}}$ & $15.8 \pm 4.7^{\mathrm{a}}$ & $5.1 \pm 4.4^{\mathrm{a}}$ & $0^{\mathrm{a}}$ \\
\hline RA & 181 & 6 & $73.5 \pm 13.9$ & $40.3 \pm 7.8^{\mathrm{a}}$ & $20.7 \pm 6.0^{\mathrm{a}}$ & $1.7 \pm 5.6^{\mathrm{a}}$ & $0^{\mathrm{a}}$ \\
\hline PVA & 210 & 7 & $78.5 \pm 10.1$ & $42.9 \pm 7.2^{\mathrm{a}}$ & $21.4 \pm 5.5^{\mathrm{a}}$ & $4.5 \pm 5.2^{\mathrm{a}}$ & $0^{\mathrm{a}}$ \\
\hline c-FCS & 214 & 9 & & $81.1 \pm 6.2^{\mathrm{b}}$ & $69.7 \pm 4.8^{\mathrm{b}}$ & $44.8 \pm 4.5^{\mathrm{b}}$ & $36.8 \pm 3.4^{b}$ \\
\hline$c-R A$ & 161 & 7 & & $82.7 \pm 7.3^{\mathrm{b}}$ & $55.1 \pm 5.6^{\mathrm{b}}$ & $28.1 \pm 5.2^{\mathrm{c}}$ & $16.1 \pm 4.0^{c}$ \\
\hline c-PVA & 154 & 7 & & $78.3 \pm 7.3^{b}$ & $60.0 \pm 5.6^{\mathrm{b}}$ & $30.8 \pm 5.2^{c}$ & $17.4 \pm 4.04^{\mathrm{c}}$ \\
\hline
\end{tabular}

$\mathrm{N}$, number of oocytes recovered after warming; R, replicates; values are least square mean (LSM) \pm standard error (SE); groups named with " $c$ " indicate fresh control group of oocytes; different superscripts differ significantly $(\mathrm{a}, \mathrm{b}, \mathrm{c} p<0.05)$. Development data refer to cultured oocytes.

FCS, fetal calf serum; RA, retinoic acid; PVA, polyvinyl alcohol.

tion of cortical granules (CG), smooth endoplasmic reticulum (SER), and lipid droplets as well as cytoplasmic vesicles.

\section{Statistical analysis}

Data from embryo development were analyzed in two steps. First, because these values can be represented by contingency tables, those factors significantly affecting the variables were identified by Categorical Data Modeling (CATMOD) using the SAS model (version 8.2, SAS Institute, Cary, NC). CATMOD extends analysis from continuous data to categorical data, fitting linear models to functions of response frequencies. Treatment and replicates were found to have significant influence on dependent variables. Second, those factors identified to be significant were used to fit a linear model using the General Linear Models (GLM; SAS). The GLM procedure was used to estimate least square means (LSM) for each fixed effect having a significant $F$ value. Duncan's multiple-range test was carried out on raw means calculated for the main effects, and data are referred to frequency percentages of oocytes.

\section{RESULTS}

Morphologic appearance of COCs immediately after warming was similar to fresh COCs in all groups; consequently, all recovered oocytes after warming were submitted to IVF. Those zygotes derived from vitrified/warmed oocytes appeared as much more fragile struc- tures than fresh controls, and removal of CC after fertilization was usually associated with fragmented cytoplasm, indistinct oolema, increased perivitelline space, or damaged zona pellucida.

Vitrification produced high rates of embryos showing degenerated appearance after IVF, as showed by the percentages of zygotes selected to be cultured on day 1 (Table 1). However, no differences between maturation treatments were detected at this stage. Zygotes derived from fresh oocytes developed up to day 7 at higher rates $(p<0.05)$ than those derived from vitrified/warmed oocytes. Oocytes matured fresh with FCS showed higher 5- to 8-cell, day 6 morulae plus blastocysts and day 7 blasto-

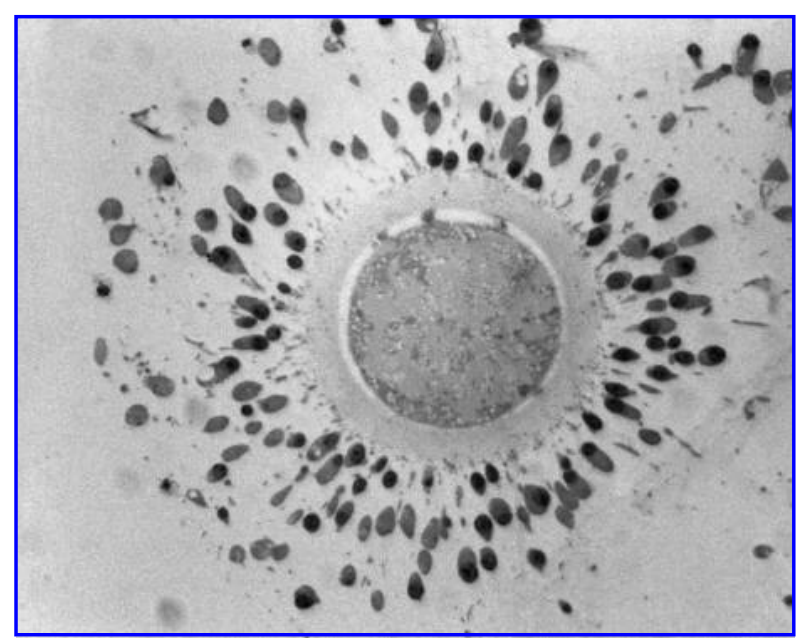

FIG. 1. Fresh complex oocyte cumulus after maturation in the presence of fetal calf serum (FCS). Cumulus cells appear expanded $(200 \times)$. 


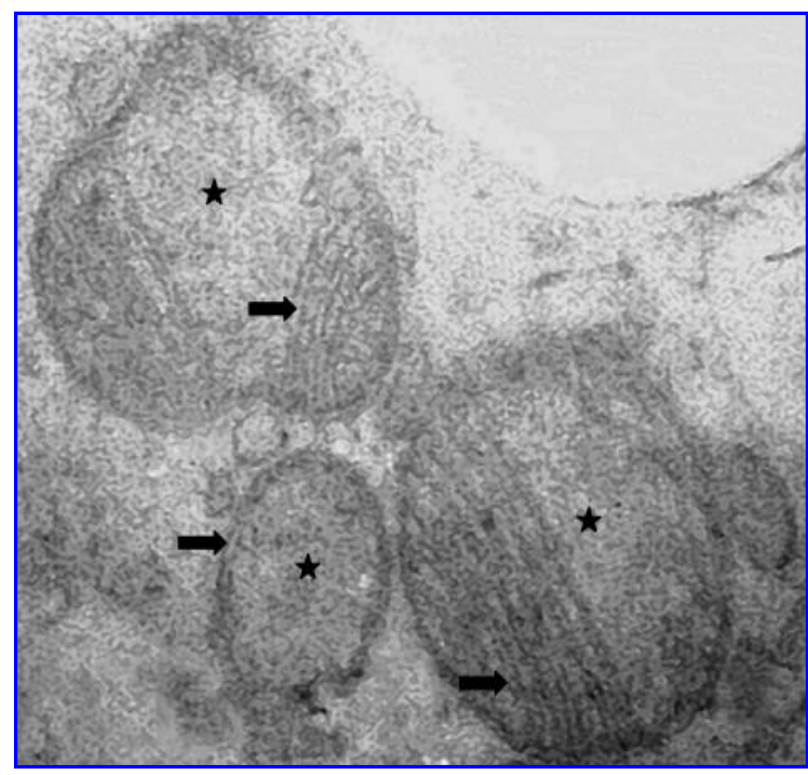

FIG. 2. Mitochondria of a vitrified/warmed oocyte from the PVA group. Crestae and the external double membrane (arrows) are observed although the matrix shows signs of vacuolization (stars) $(44,000 \times)$.

cysts rates than their counterparts matured with PVA and RA. No blastocysts were obtained in any treatment from vitrified/warmed oocytes.

\section{Ultrastructural study}

Vitrification/warming of oocytes matured both with FCS and PVA yielded similar alter-

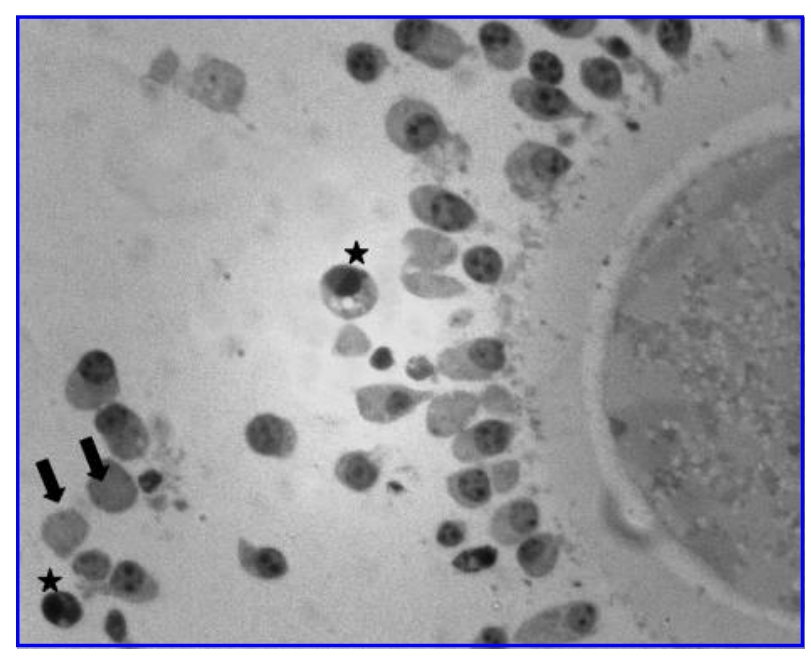

FIG. 3. Fresh complex oocyte cumulus matured with 9-cis-retinoic acid (RA). Cumulus cells present nuclei showing lysis (arrow) and apoptosis (stars) phenomena $(400 \times)$. ations. The CC remained expanded around oocytes after vitrification (Fig. 1), but these cells contained a large number of cytoplasmic vacuoles that appeared to damage the plasma membrane. Necrotic nuclei were observed within these cells. Moreover, most cumulus cells projections appeared to be damaged and interrupted. In the oocyte the periviteline space was smaller, and cytoplasmic vesicles migrated peripherally. These vesicles became confluent and often disrupted the oolema. The numbers of CG in the ooplasm decreased and we observed an abnormal CG premature release into the periviteline space. Mitochondria exhibited extensive vacuolization and scarce crestae, although the mitochondrial double membrane was mostly conserved (Fig. 2).

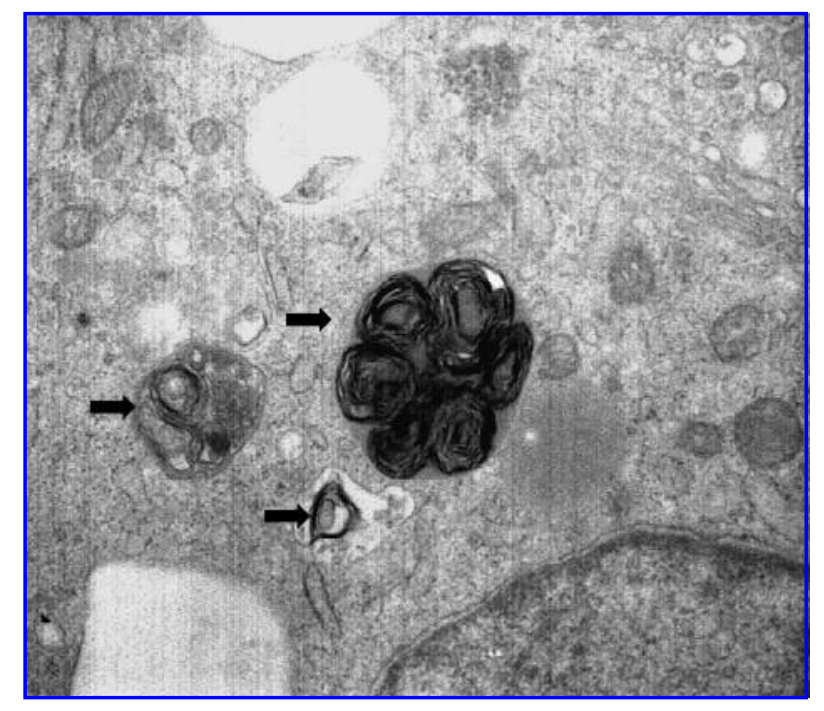

FIG. 4. Residual bodies (arrows) from a vitrified/ warmed oocyte matured with 9-cis-retinoic acid (RA) $(32,000 \times)$.

Similar to oocytes matured with FCS and PVA, vitrified/warmed oocytes matured with 9-cis-RA showed cumulus cells expansion, although a lower incidence of necrotic nuclei (Fig. 3). Mitochondria appeared swollen, with degeneration of the internal structures, but keeping the integrity of the double membrane. The most interesting finding in this group of oocytes was the high numbers of residual bodies present in the cytoplasm of both cumulus cells and oocytes. This structure appeared as electron-dense with an evident membrane (Fig. 
4). Oocytes vitrified and warmed showed lipid vesicles darker than fresh controls.

\section{DISCUSSION}

In this work we analyzed the ability of 9-cisRA to influence the development and the ultrastructural appearance of the vitrified oocyte matured with 9-cis-RA. Within all experimental groups, vitrification of oocytes increased degeneration after IVF, and embryonic development rates from days 3 to 7 were lower than fresh controls. We did not obtain blastocysts from vitrified/warmed oocytes.

Morphologic appearance of COCs immediately after warming was normal (i.e., comparable to fresh, unvitrified COCs), allowing selection of all COCs for IVF. However, signs of degeneration (fragmented cytoplasm, indistinct oolema, increased perivitelline space, or damaged zona pellucida) were observed at the onset of culture. In addition, zygotes from vitrified and warmed oocytes appeared much more fragile, and removal of CC was usually associated to damage to the zona pellucida and plasma membrane.

Men et $a .^{8}$ reported that composition of IVM medium influences cryosurvival. These authors replaced FSH for $\mathrm{LH}$ and found improved cryoresistance of the MII bovine oocyte. In our experiments, maturation media contained gonadotropins FSH and LH, added either with FCS, PVA, or 9-cis-RA, and no differences among maturation protocols were found in terms of survival after warming. Our degeneration percentages were lower, while cleavage rates were higher than those obtained by other authors, 9,18,19 with the development up to the morula and blastocyst stage being compromised. The low correlation we found between cleavage and subsequent embryonic development has been cited elsewhere. ${ }^{9,15}$ In the present work we did not obtain blastocysts from vitrified/warmed oocytes, but development rates up to day 6 were comparable to our previous work. ${ }^{1}$ Many other works reported controversial results after vitrification and warming of bovine oocytes, 7,9,15,18-21 with observed differences being probably based on maturation media, cryoprotectants, and in vitro culture system. Live calves have been cited to arise from vitrified and warmed immature oocytes. ${ }^{15}$

The altered morphology observed in vitrified/warmed COCs matured both with FCS and PVA, agrees with the findings of Fuku et al., ${ }^{3,4}$ who suggested that exposure to cryoprotectants together with low temperatures may contribute to migration and fusion of vesicles in the oolema, causing major damage at the level of the plasma membrane. In our work, most gap junctions, which communicate intercellularly with CC and oocytes during the IVM process, appeared as damaged and interrupted. Mitochondria exhibited extensive vacuolization, swelling, and disappearance of most crestae. Within the oocyte, we observed premature release of GC into the periviteline space. The periviteline space was reduced. The crestae of the mitochondria were electrondense, as a sign of morphologic alteration in the organelle, but the double membrane was conserved in most cases. Vesicles within the SER were more numerous than in fresh oocytes, and they appeared isolated from the mitochondria. Organization and metabolic activity of mitochondria are necessary features of cytoplasmic maturation and meiotic resumption. ${ }^{22}$ In bovine oocytes the major relocation of mitochondria occurs during IVM and it is influenced by hormones and energy substrates in the maturation medium. ${ }^{24}$ The mitochondrial swelling observed in our vitrified/warmed oocytes can be responsible for an impaired development of these oocytes. In accordance with other authors, ${ }^{1-4,7,24}$ ultrastructural findings in our work seriously compromised embryo development. On the other hand, vitrified/ warmed COCs matured with 9-cis-RA showed CC with an expansion degree comparable to those in FCS and PVA, whereas alterations in GJ appeared to be reduced, with mitochondria showing fewer degenerative signs. Interestingly, we found a high, unusual concentration of residual bodies in both CC and the oocyte. Residual bodies derive from lysosomes, which are membrane-bounded cytoplasmic vesicles enclosing 50 or more essentially hydrolytic enzymes. The boundary lysosomal membrane selectively admits substrates and protects the host cell from digestion by enclosed enzymes. ${ }^{25}$ 
The origin of many of these residual bodies cannot be determined from their ultrastructure, but their number is notable in metabolically active cells. Skeletal cells treated with vitamin A in an organ culture show increased activity of releasing lysosomal enzymes and higher population of residual bodies. ${ }^{26}$ On the other hand, the administration of cyclosporine A to rats increases the occurrence of numerous anomalous spermatids and residual bodies in the epididymal ducts. ${ }^{27}$ To the best of our knowledge, no data about the presence of residual bodies in COCs have been provided. It should be hypothesized that the presence of RA, together with the cryodamage derived from the vitrification protocol produced this alteration, because it is not observed in the fresh oocyte treated with 9-cis-RA or in oocytes vitrified in the absence of 9-cis-RA.

We conclude that cryopreservation causes bovine oocytes to undergo degeneration during subsequent culture. In agreement with Men and coworkers ${ }^{7,8}$ the reduced developmental competence of our vitrified and warmed oocytes depends on cryodamage inflicted to the oocytes. Upon characterization of the mechanisms explaining degeneration within cryopreserved oocytes, improvements in oocyte cryopreservation could be possible by the addition of inhibitors in the cryopreservation solution and/or cell culture media.

\section{ACKNOWLEDGMENT}

Supported by MCYT-FEDER; project AGL2001-0379.

\section{REFERENCES}

1. Diez C, Duque P, Gómez E, et al. Bovine oocyte vitrification before or after meiotic arrest: effects on ultrastructure and developmental ability. Theriogenology 2005;64:317-333.

2. Faerge I, Mayes P, Hyttel P, et al. Nuclear ultrastructure in bovine oocytes after inhibition of meiosis by chemical and biological inhibitors. Mol Reprod Dev 2001;59:459-467.

3. Fuku E, Liu J, Downey BR. In vitro viability and ultrastructural changes in bovine oocytes treated with a vitrification solution. Mol Reprod Dev 1995;40: 177-185.
4. Fuku E, Xia L, Downey BR. Ultrastructural changes in bovine oocytes cryopreserved by vitrification. Cryobiology 1995;32:139-156.

5. Isachenko V, Isachenko E, Michelmann HW, et al. Lipolysis and ultrastructural changes of intracellular lipid vesicles after cooling og bovine and porcine GVoocytes. Anat Histol Embryol 2001;30:333-338.

6. Lonergan P, Faerge, I, Hyttel PD, et al. Ultrastructural modifications in bovine oocytes maintained in meiotic arrest in vitro using roscovitine or butyrolactone. Mol Reprod Dev 2003;64:369-378.

7. Men H, Monson RL, Parrish JJ, et al. Detection of DNA damage in bovine metaphase II oocytes resulting from cryopreservation. Mol Reprod Dev 2003;64:245-250.

8. Men H, Monson RL, Rutledge JJ. Effect of meiotic stages and maturation protocols on bovine oocyte's resistance to cryopreservation. Theriogenology 2002; 57:1095-1103.

9. Hochi S, Ito K, Hirabayashi M, et al. Effect of nuclear stages during IVM on the survival of vitrifiedwarmed bovine oocytes. Theriogenology 1998;49: 787-796.

10. Hochi S. Cryopreservation of follicular oocytes and preimplantation embryos in cattle and horses. I Reprod Dev 2003;49:13-21.

11. Zeron Y, Pearl M, Borochov A, et al. Kinetic and temporal factors influence chilling injury to germinal vesicle and mature bovine oocytes. Cryobiology 1999;38:35-42.

12. Gómez E, Rodríguez A, Goyache F, et al. Retinoid-dependent mRNA expression and poly-(A) contents in bovine oocytes meiotically arrested and/or matured in vitro. Mol Reprod Dev 2004;69:101-108.

13. Hidalgo CO, Díez C, Duque P, et al. Pregnancies and improved early embryonic development in bovine oocytes matured in vitro with 9-cis-retinoic acid. Reproduction 2003;125:409-416.

14. Duque P, Díez C, Royo LJ, et al. Enhancement of developmental capacity of meiotically inhibited bovine oocytes by retinoic acid. Hum Reprod 2002;17: 2706-2714.

15. Vieira AD, Mezzalira A, Barbieri DP, et al. Calves born after open pulled straw vitrification of immature bovine oocytes. Cryobiology 2002;45:91-94.

16. Parrish JJ, Susko-Parrish JL, Leibifried-Ruthledge ML, et al. Bovine in vitro fertilization with frozen-thawed semen. Theriogenology 1986;25:591-600.

17. Holm P, Booth PJ, Schmidt MH, et al. High bovine blastocyst development in a static in vitro production system using SOFaa medium supplemented with sodium citrate and myo-inositol with or without serum-proteins. Theriogenology 1999;52:683-700.

18. Arav A, Shehu D, Mattioli M. Osmotic and cytotoxic study of vitrification of immature bovine oocytes. I Reprod Fert 1993;99:353-358.

19. Asada M, Ishibashi S, Ikumi S, et al. Effect of polyvinyl alcohol (PVA) concentration during vitrification of in vitro matured bovine oocytes. Theriogenology 2002;58:1199-1208.

20. Chian RC, Kuwayama M, Tan L, et al. High survival 
rate of bovine oocytes matured in vitro following vitrification. L Reprod Dev 2004;50:685-696.

21. Vajta G. Oocyte and embryo vitrification. Reprod Dom Anim 1999;6(Suppl):45-48.

22. Cummins J. Mitochondrial DNA in mammalian reproduction. Rev Reprod 1998;3:172-182.

23. Bavister BD. Interactions between embryos and the culture medium. Theriogenology 2000;53:619-626.

24. Aman RR, Parks JE. Effects of cooling and rewarming on the meiotic spindle and chromosomes of in vitro matured bovine oocytes. Biol Reprod 1994;50:103-110.

25. Weiss L. The cell. In: Cell and Tissue Biology, A Text Book of Histology, 6th ed. Baltimore/Munich: Urban and Schwarzenber; 1988:115-150.

26. Kerr JFR. Some lysosome functions in liver cells reacting to sublethal injury. In: Dingle JT, ed. Lysosomes in Biology and Pathology. London: North-Holland American Elsevier; 1973.
27. Masuda H, Fujihira S, Ueno H, et al. Ultrastructural study on cytotoxic effects of cyclosporine A in spermiogenesis in rats. Med Electron Microsc. 2003; 36:183-191.

Address reprint requests to: Carmen Díez Area de Genética y Reproducción SERIDA

Camino de los Claveles 604 33203 Somió Gijón Spain

E-mail: mcdiez@serida.org 